\title{
Fitness consultations in routine care of patients with type 2 diabetes in general practice: an 18-month non-randomised intervention study
}

\author{
Henning Lohmann ${ }^{1,2^{*}}$, Volkert Siersma ${ }^{2}$, Niels F Olivarius ${ }^{2}$
}

\begin{abstract}
Background: Increasing physical activity is a cornerstone in the treatment of type 2 diabetes and in general practice it is a challenge to achieve long-term adherence to this life style change. The aim of this study was to investigate in a non-randomised design whether the introduction of motivational interviewing combined with fitness tests in the type 2 diabetes care programme was followed by a change in cardio-respiratory fitness expressed by $\mathrm{VO}_{2 \text { max }}$ muscle strength of upper and lower extremities, haemoglobin $\mathrm{A}_{1 c}\left(\mathrm{HbA}_{1 c}\right)$ and HDL-cholesterol.
\end{abstract}

Methods: Uncontrolled 18-month intervention study with follow-up and effect assessment every 3 months in a primary care unit in Denmark with six general practitioners (GPs). Of 354 eligible patients with type 2 diabetes, 127 (35.9\%) were included. Maximum work capacity was tested on a cycle ergometer and converted to $\mathrm{VO}_{2 \max }$. Muscle strength was measured with an arm curl test and a chair stand test. The results were used in a subsequent motivational interview conducted by one of the GPs. Patients were encouraged to engage in lifestyle exercise and simple home-based self-managed exercise programmes. Data were analysed with mixed models.

Results: At end of study, 102 (80.3\%) participants remained in the intervention. Over 18 months, $\mathrm{VO}_{2 \text { max }}$ increased $2.5 \%(p=0.032)$ while increases of $33.2 \%(p<0.001)$ and $34.1 \%(p<0.001)$ were registered for the arm curl test and chair stand test, respectively. HDL-cholesterol increased $8.6 \%(p<0.001)$, but HbA $\mathrm{H}_{1 c}$ remained unchanged $(p=$ $0.57)$ on a low level (6.8\%). Patients without cardiovascular disease or pain from function limitation increased their $\mathrm{VO}_{2 \max }$ by $5.2 \%(\mathrm{p}<0.0001)$ and $7.9 \%(\mathrm{p}=0.0008)$, respectively.

Conclusions: In this 18-month study, participants who had repeated fitness consultations, including physical testing and motivational interviewing to improve physical activity, improved $\mathrm{VO}_{2 \max }$, muscle strength, and lipid profile. Our results indicate that physical testing combined with motivational interviewing is feasible in a primary health care setting. Here, a fitness consultation tailored to the individual patient, his/her comorbidities and conditions in the local area can be incorporated into the diabetes programme to improve patients' muscle strength and cardio-respiratory fitness.

\section{Background}

Increases in cardio-respiratory fitness, muscle strength and level of physical activity are associated with decreased mortality and protect against age-related disabilities [1-7]. A substantial proportion of patients with type 2 diabetes have low levels of physical fitness and do not engage in the recommended level of physical activity $[1,8]$. These

\footnotetext{
* Correspondence: Lohmann@dadlnet.dk

${ }^{1}$ General practice, Korsør, Denmark

Full list of author information is available at the end of the article
}

patients have increased cardiovascular mortality [9] and many comorbidities [10], e. g. hypertension, cardiovascular disease and arthritis, which may preclude some physical activities or require evaluation by a physician before the activities can be undertaken.

Regular exercise in type 2 diabetic individuals may have a significant effect on $\mathrm{VO}_{2 \max }$ and may result in decreased HbA1c [11,12]. Similarly, HDL-cholesterol increases with cardio-respiratory fitness $[13,14]$. It has also been demonstrated that progressive resistance

\section{Ciomed Central}


training increases muscle strength in type 2 diabetic patients [15].

Interventions that include fitness testing and individual exercise prescription are associated with more effect on fitness outcomes than interventions without these elements [16], and in recent years the use of individual behavioural approaches to increase physical activity has been advocated. It seems relevant to use motivational interviewing and include testing of muscle strength, cardio-respiratory fitness as well as exercise prescription in the motivational armamentarium of a diabetes care programme [17-22]. In a study of home-based resistance training in elderly people it was concluded that a positive attitude towards exercise and a sense of control over it were associated with adherence to the exercise regimen [23]. There are many laboratory studies with supervised exercise that demonstrate an effect on cardiovascular fitness and muscle strength, but results from general practice are scarce [11].

The over-all purpose of the present study was to see whether it was feasible for general practitioners (GPs) and their staff to motivate people with type 2 diabetes to increase and maintain their muscle strength and cardiorespiratory fitness by self-managed physical activities during an 18-month intervention period. We assumed that by providing patients with knowledge of their own muscle strength and cardio-respiratory fitness, they would become aware of discrepancies between their current physical fitness and personal goals for future health, and this realisation could induce behavioural changes $[16,20]$. In those patients who accepted to undergo the intervention, we measured a number of outcomes before, during and after the inclusion of fitness tests and motivational interviewing in the patients' regular diabetes control consultations. The primary outcomes were $\mathrm{VO}_{2 \max }$ (maximal oxygen uptake, $\mathrm{ml} \mathrm{O}_{2} \mathrm{~kg}^{-1} \mathrm{~min}^{-1}$ ), muscle strength of upper and lower extremities, haemoglobin $\mathrm{A}_{1 \mathrm{c}}\left(\mathrm{HbA}_{1 \mathrm{c}}\right)$, and HDL-cholesterol during the 18-month intervention period. Secondary outcomes were waist circumference, body mass index (BMI), systolic and diastolic blood pressure, fasting plasma glucose, total cholesterol, LDL-cholesterol, and triglycerides.

\section{Methods}

\section{Study design and participants}

The study was designed as an uncontrolled study in a primary health care unit with six GPs providing health services to approx. half of the 20,000 population of a town in Denmark. All health care providers in the unit participated. In Denmark, routine care of patients with type 2 diabetes is usually given by GPs and practice nurses in primary care units in a national structured diabetes programme recommending control every 3 months.
Of 399 patients with known type 2 diabetes, 127 were included (Figure 1). All were Caucasians. During the study, participants were considered lost to follow-up after non-response to one reminder. The reasons for exclusion or loss to follow-up appear from Figure 1. The ethics committee of West Zealand approved the protocol. Patients gave written informed consent.

\section{The fitness consultation}

The six GPs involved were trained in the principles of aerobic and resistance exercise testing and training in a 3-hour session, and they were introduced to the strategies and techniques of motivational interviewing in another 3-hour session conducted by a researcher with wide experience of motivational interviewing.

During the 18 months of intervention, the patients were seen on two different days every three months in connection with the scheduled visits in the usual diabetes care programme.

On the first day, the practice nurse or the laboratory technician tested maximum work capacity (Watt $t_{\max }$ ) and muscle strength and measured weight, height, waist circumference, blood pressure and $\mathrm{HbA}_{1 \mathrm{c}}$. At baseline and after 9 and 18 months, fasting plasma glucose, total cholesterol, HDL-cholesterol, fasting triglycerides, serum creatinine, $\mathrm{HbA}_{1 \mathrm{c}}$, and urinary albumin/creatinine-ratio were measured as well.

On the second day, the GPs, in conjunction with the usual diabetes control, carried out a fitness consultation. At every fitness consultation the GPs had to judge and note in the patient file the patient's position in relation to the Stages of change model (Pre-contemplation, Contemplation, Preparation, Action, Maintenance and Relapse). The consultation was then held bearing this knowledge in mind. The doctors and patients worked with ambivalent attitudes, using the results of the physical tests, the pro and cons of increased physical activity, resistance, readiness and ability to change. The GPs were recommended not to try to persuade patients to certain behaviour changes but to accept the choices made by the patients.

Results of the physical tests were presented to the patient using age- and sex-stratified nomograms and information about changes since the previous visit $[2,24]$. Life-style exercise, i.e. increasing physical activity in daily life, actions such as walking up and down stairs instead of using the lift, cycling instead of using the car, gardening etc., were suggested. A realistic goal of physical activity was negotiated, aiming at $2,500 \mathrm{kcal}$ per week corresponding to approximately a half-hour walking and a half-hour cycling a day seven days a week. This is a level where the maximal effect on cardiovascular risk and $\mathrm{HbA}_{1 \mathrm{c}}$ might be expected $[4,25,26]$. 
Inclusion criterion:

All patients on the practice list with known type 2 diabetes according to WHO criteria $(n=399)$

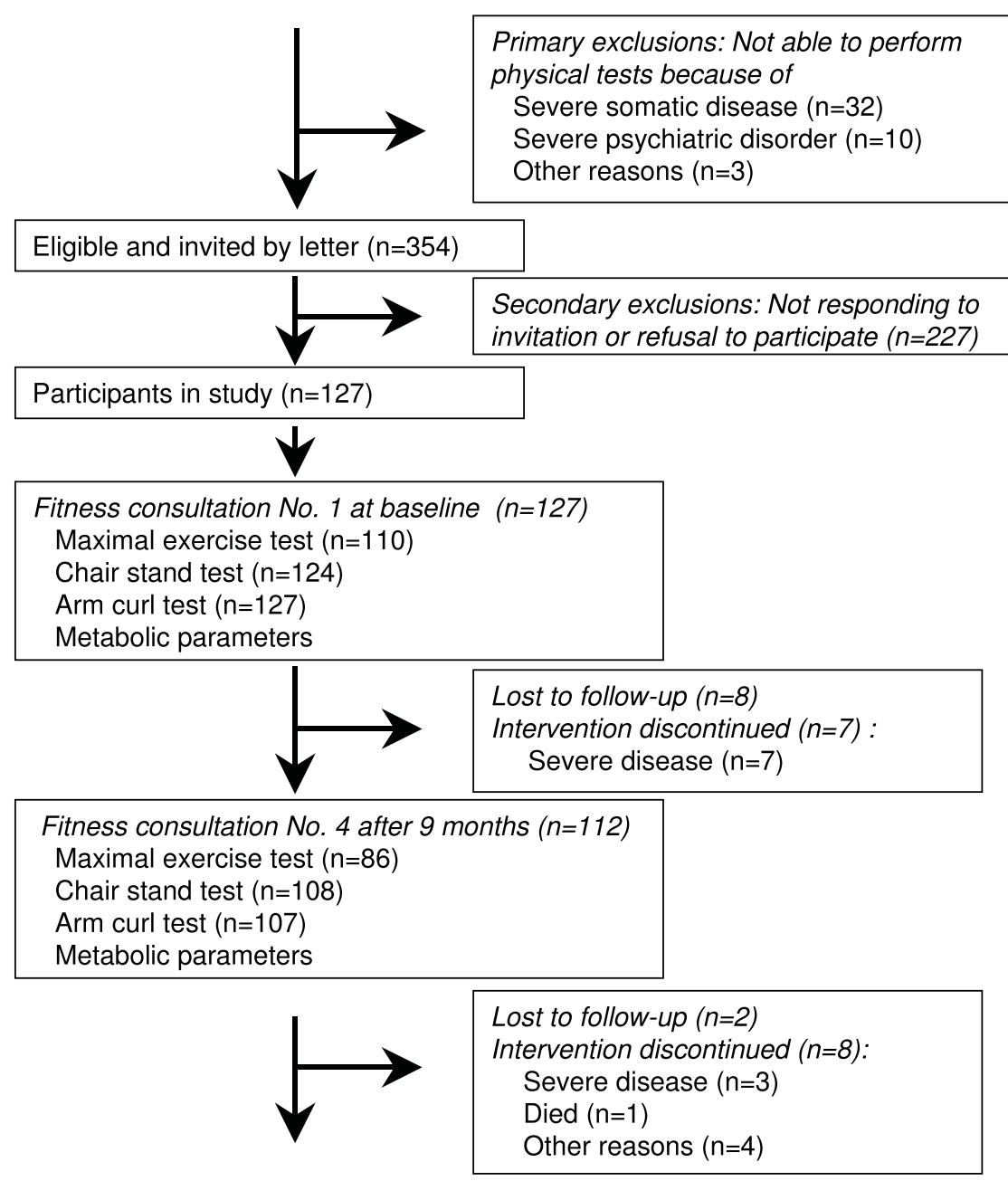

Fitness consultation No. 7 after 18 months $(n=102)$

Maximal exercise test $(n=70)$

Chair stand test $(n=91)$

Arm curl test $(n=90)$

Metabolic parameters

Figure 1 Flow of patients through the trial and the number of different physical tests done at fitness consultation No. 1, 4 and 7

Self-managed resistance exercise was suggested for each of the major muscle groups three times a week gradually progressing to two or three sets with a resistance that could be done between a minimum of 10 times and a maximum of 15 times [24].

\section{Tests of fitness and muscle strength}

Before testing, all patients had a 6-minute light warm-up period on the bicycle ergometer with $50 \%$ of maximum workload. Tests of muscle strength were done as described in "Senior Fitness Test" [2] by two tests: (a) an arm curl test during which the patient lifted weights from full extension to maximum flexion as many times as possible within 30 seconds. The outcome was the number of flexions; (b) a chair stand test where the patient stood up and sat down from a $40 \mathrm{~cm}$ high chair as many times as possible within 30 seconds. The outcome was the number of stand ups. The chair stand test is a measure of lower body strength and has a moderately high correlation to leg press scores ( $R=0.78$ for men and $R=0.71$ for women). 
The arm curl test is a measure of upper body strength and has a moderately high correlation to combined 1-RM (repetition max) biceps, chest, and upper back $(\mathrm{R}=0.84$ for men and $\mathrm{R}=0.79$ for women). The test-retest reliability (95\% confidence interval) for the chair stand test is 0.89 (0.79-0.93) and for the arm curl test $0.81(0.72-0.88)$ [2].

Cardio-respiratory fitness was tested with an individualized symptom-limited ramp cycle ergometer (Monark ${ }^{\circ}$ ) test where we used a protocol with an individualized initial workload and a 12.5-watt increase per min. aiming at a testing time between six and 10 minutes. The results, i.e. the Watt $\mathrm{max}_{\max }$ attained, were converted to $\mathrm{VO}_{2 \max }(\mathrm{ml}$ $\mathrm{O}_{2} \mathrm{~kg}^{-1} \mathrm{~min}^{-1}$ ) by use of conversion formulas [27]. This method of measuring cardio-respiratory fitness has a high correlation, $R=0.97$, with measurements of pulmonary ventilation and gas exchange [27].

We did not screen all participants with stress testing before exercise testing, but all were assessed clinically and with a resting ECG with regard to the risk of ischaemic heart disease and, at the discretion of the GP, referred to a cardiologist before testing [28]. Contraindications for the maximal exercise test were blood pressure $>180 / 110 \mathrm{mmHg}$, unstable angina pectoris, severe ischaemia on resting ECG, severe heart arrhythmia, aorta stenosis, pacemaker with fixed heart rate, autonomic neuropathy (resting heart rate $>100 \mathrm{bpm}$, orthostatic vertigo), proliferative retinopathy, and acute disease [24,28]. Patients on insulin treatment with blood glucose $<7 \mathrm{mmol} / \mathrm{l}$ were given $20 \mathrm{~g}$ glucose 15 minutes before testing. All tests were stopped if the patient felt unwell in any way. The health centre had access to resuscitation equipment including a heart starter.

\section{Biochemical and clinical variables}

All blood samples were taken in the morning after an eight-hour overnight fast and a resting period of at least $15 \mathrm{~min}$ and no hard physical activity within the foregoing two hours. Samples were analysed at Slagelse Hospital. Fraction of $\mathrm{HbA}_{1 \mathrm{c}}$ was measured by a high performance liquid chromatography method (a Tosoh Automated Glycohaemoglobin Analyzer HLC-723 G. Reference interval: 0.042-0.063). Serum total cholesterol concentration was measured enzymatically with cholesterol esterase-cholesterol oxidase-peroxidase reagent. Serum triglyceride concentrations were determined enzymatically with a lipase-glycerolkinase-glycerol-3phosphate oxidase-peroxidase reagent. HDL-cholesterol was determined by a homogeneous enzymatic colorimetric method. Plasma glucose was measured by a hexokinase method. In freshly voided morning urine, creatinine was determined by a Jaffé reaction and albumin by an immunoturbidimetric method.

Body weight and height were measured without shoes and outer garments on the same scales throughout the study. BMI was calculated as (weight in $\mathrm{kg}$ )/(height in metres) ${ }^{2}$. Waist circumference was measured to the nearest $\mathrm{cm}$ in the mid-horizontal plane between lowest rib and iliac crest. Blood pressure was measured after $10 \mathrm{~min}$. rest in the seated position as the lowest of three values using a mercury sphygmomanometer.

Pain with function limitation was defined as pain from joints and/or muscles in arms, shoulders, legs and/or back which reduced the performance at the physical tests at the 9- and/or 18-month follow-up as indicated by the patient. Cardiovascular disease (CVD) was defined as history of myocardial infarction and/or verified stenosis of coronary arteries and/or stroke and/or arteriosclerosis of the lower extremities verified by distal pressure measurement recorded at baseline and/or after 9 and/or 18 months.

\section{Statistical analysis}

Differences between study subjects and excluded patients were investigated by $\chi^{2}$ tests or Kruskal-Wallis tests. The development of each outcome variable was described in a mixed model with a separate fixed effect for each examination, and a random patient intercept [29]. The concatenation of fixed effects was interpreted as the average development of the outcome, and was superimposed on the cross-sectional distributions of the outcome (shown as box-plots) in Figure 2. Whether the outcome remains the same over time was tested by a Wald test for the null hypothesis that all parameters of the fixed effects were the same. A heuristic measure of increase was $\Delta$ : the difference between the modelled baseline outcome and the modelled outcome at the seventh examination. A power calculation shows that the study has a power of $80 \%$ to detect a difference in change in $\mathrm{VO}_{2 \max }$ from 0 (no change) to $1.3 \mathrm{ml} \mathrm{O}_{2} \mathrm{~kg}^{-1} \mathrm{~min}^{-1}$ during 18 months when $\mathrm{n}=127$.

Subgroup analyses were done by adding the stratification variable to the mixed model both as a main fixed effect and interacting with the fixed effects of the separate examinations. This allowed for completely different developments in the subgroups. The test for the significance of the difference between the developments was the Wald test for the null hypothesis that all parameters of fixed effects containing the subgroup variable were zero. Here $\Delta$ was the difference between the subgroupspecific modelled baseline and seventh examination outcome. Significance of the comparison tests was determined controlling for the false discovery rate at 5\% [30]. Data were analysed with SAS PROC MIXED.

\section{Results}

Of 354 eligible patients, 127 (35.9\%) participated in the study. There was no statistically significant difference between the 227 non-responders and the 127 participants with regard to age $(67.5 / 67.0$ years, $\mathrm{p}=0.77)$, 


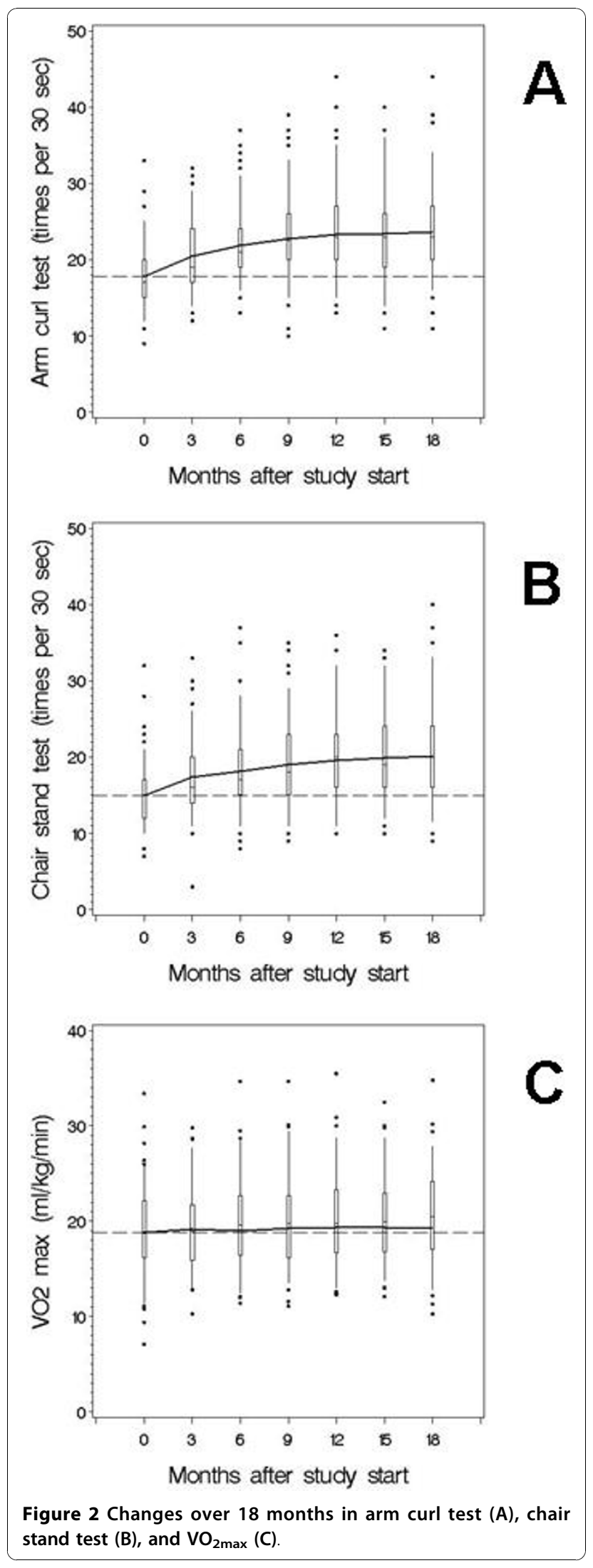

gender (women, 42.3/42.5\%, $\mathrm{p}=0.96$ ) and $\mathrm{HbA}_{1 \mathrm{c}}$ $(6.8 / 6.9 \%, p=0.30)$ before the start of intervention (Figure 1). At baseline, participants were characterised by a low $\mathrm{HbA}_{1 \mathrm{c}}$ and a high comorbidity (Table 1 ). Thirteen patients had atypical courses due to severe disease (myocardial infarction, stroke, accidents, and cancer) and one patient started participation in a placebo trial after inclusion. Test results from these patients were excluded from analysis from the date of the event.

\section{Primary outcome measures}

Over the 18 months, clear average increases of approximately one third were obtained for both arm curl test and chair stand test, while $\mathrm{VO}_{2 \max }$ increased moderately (Table 2). The average increase in muscle strength abated over the 18 months but never declined (Figure 2). $\mathrm{HDL}$-cholesterol also increased, but $\mathrm{HbA}_{1 \mathrm{c}}$ remained unchanged on a low level.

\section{Subgroup analyses}

The development of $\mathrm{VO}_{2 \max }$ varied with age, sex, CVD and pain with function limitation (Table 2). In a full

\section{Table 1 Baseline characteristics of the patients}

\begin{tabular}{|c|c|}
\hline Characteristic & \\
\hline Sex (men/women) & $73(57 \%) / 54(43 \%)$ \\
\hline Age (years) & $67.0(59.8-73.8)$ \\
\hline Diabetes duration (years) & $3(2-8)$ \\
\hline School education (basic/further) & $39(31 \%) / 88(69 \%)$ \\
\hline Marital status (single/cohabiting) & $29(23 \%) / 98(77 \%)$ \\
\hline $\mathrm{VO}_{2 \max }\left(\mathrm{ml} \mathrm{kg}{ }^{-1} \min ^{-1}\right)$ & $19.0(17.0-22.5)$ \\
\hline Arm curl test (times per $30 \mathrm{sec}$ ) & $17(14-19)$ \\
\hline Chair stand test (times per $30 \mathrm{sec}$ ) & $14(12-17)$ \\
\hline Haemoglobin $A_{1 c}(\%)$ & $6.8(6.4-7.5)$ \\
\hline HDL-cholesterol (mmol/l) & $1.3(1.1-1.5)$ \\
\hline Total cholesterol $(\mathrm{mmol} / \mathrm{l})$ & $5.0(4.2-5.6)$ \\
\hline LDL-cholesterol (mmol/l) & $2.7(2.2-3.3)$ \\
\hline Fasting triglycerides (mmol/l) & $1.5(1.1-2.3)$ \\
\hline Waist circumference (cm, men) & $105(101-115)$ \\
\hline Waist circumference (cm, women) & $99(92-107)$ \\
\hline Body mass index $\left(\mathrm{kg} / \mathrm{m}^{2}\right)$ & $29.6(26.3-33.3)$ \\
\hline Systolic pressure $(\mathrm{mmHg})$ & $140(130-150)$ \\
\hline Diastolic pressure $(\mathrm{mmHg})$ & $80(75-85)$ \\
\hline Fasting plasma glucose $(\mathrm{mmol} / \mathrm{l})$ & $7.7(6.8-9.1)$ \\
\hline Antihypertensive medication $(\mathrm{N} / \mathrm{Y})$ & $36(28 \%) / 91$ (72\%) \\
\hline $\begin{array}{l}\text { Antidiabetic treatment (diet/oral agents/ } \\
\text { insulin) }\end{array}$ & $\begin{array}{l}37(29 \%) / 70(55 \%) / 20 \\
(16 \%)\end{array}$ \\
\hline Statin treatment $(N / Y)$ & 49 (39\%)/78 (61\%) \\
\hline Smoking $(N / Y)$ & $99(78 \%) / 28(22 \%)$ \\
\hline Albumin/creatinine ratio $(\leq 3.5 />3.5)$ & $97(76 \%) / 30(24 \%)$ \\
\hline Cardiovascular disease $^{\mathrm{a}}(\mathrm{N} / \mathrm{Y})$ & $61(48 \%) / 66(52 \%)$ \\
\hline Pain with function limitation ${ }^{\mathrm{b}}(\mathrm{N} / \mathrm{Y})$ & $53(42 \%) / 74(58 \%)$ \\
\hline
\end{tabular}

${ }^{\mathrm{b}}$ Recorded after 9 and/or 18 months. 
Table 2 Developments in primary outcome measures during the study according to baseline variables

\begin{tabular}{|c|c|c|c|c|c|c|c|c|c|c|c|c|c|c|c|c|c|c|c|c|c|c|}
\hline & & \multirow[b]{2}{*}{$n$} & \multicolumn{4}{|c|}{$\begin{array}{c}\mathrm{VO}_{2 \max } \\
(\mathrm{ml} / \mathrm{kg} / \mathrm{min})\end{array}$} & \multicolumn{4}{|c|}{$\begin{array}{l}\text { Arm curl test } \\
\text { (times per } 30 \mathrm{sec} \text { ) }\end{array}$} & \multicolumn{4}{|c|}{$\begin{array}{l}\text { Chair stand test } \\
\text { (times per } 30 \mathrm{sec} \text { ) }\end{array}$} & \multicolumn{4}{|c|}{$\begin{array}{c}\text { Haemoglobin } A_{1 c} \\
(\%)\end{array}$} & \multicolumn{4}{|c|}{$\begin{array}{l}\text { HDL-cholesterol } \\
(\mathrm{mmol} / \mathrm{l})\end{array}$} \\
\hline & & & $\Delta$ & SE & $\%$ & $p^{\mathrm{a}}$ & $\Delta$ & SE & $\%$ & $p^{\mathrm{a}}$ & $\Delta$ & SE & $\%$ & $p^{\mathrm{a}}$ & $\Delta$ & SE & $\%$ & $p^{\mathrm{a}}$ & $\Delta$ & SE & $\%$ & $p^{\mathrm{a}}$ \\
\hline Total & & 127 & 0.46 & 0.20 & 2.5 & 0.032 & 5.9 & 0.30 & 33.2 & $<0.0001$ & 5.1 & 0.31 & 34.1 & $<0.0001$ & 0.020 & 0.066 & 0.3 & 0.57 & 0.11 & 0.02 & 8.6 & $<0.0001$ \\
\hline \multirow[t]{2}{*}{ Sex } & Male & 73 & 0.58 & 0.26 & 2.9 & * & 6.3 & 0.40 & 34.2 & & 5.6 & 0.40 & 36.4 & & -0.069 & 0.088 & -1.0 & & 0.09 & 0.03 & 7.0 & \\
\hline & Female & 54 & 0.34 & 0.31 & 2.0 & & 5.3 & 0.46 & 31.8 & & 4.4 & 0.47 & 31.0 & & 0.129 & 0.098 & 1.8 & & 0.14 & 0.03 & 10.2 & \\
\hline \multirow[t]{2}{*}{ Age } & $\leq 67$ years & 63 & 0.58 & 0.26 & 2.7 & * & 7.0 & 0.42 & 37.9 & * & 6.0 & 0.41 & 37.9 & * & 0.042 & 0.092 & 0.6 & & 0.10 & 0.03 & 8.1 & \\
\hline & $>67$ years & 64 & 0.32 & 0.31 & 2.0 & & 4.7 & 0.43 & 27.8 & & 4.1 & 0.45 & 29.2 & & -0.002 & 0.096 & -0.0 & & 0.13 & 0.03 & 9.3 & \\
\hline \multirow[t]{2}{*}{ Diabetes duration } & $\leq 1$ year & 31 & 0.16 & 0.37 & 0.8 & & 7.0 & 0.60 & 38.4 & & 6.8 & 0.58 & 45.2 & * & -0.066 & 0.130 & -1.0 & & 0.14 & 0.04 & 10.0 & \\
\hline & $>1$ year & 96 & 0.58 & 0.23 & 3.2 & & 5.5 & 0.35 & 31.2 & & 4.5 & 0.36 & 30.0 & & 0.049 & 0.077 & 0.7 & & 0.11 & 0.03 & 8.1 & \\
\hline \multirow[t]{2}{*}{ School education } & Further & 88 & 0.56 & 0.23 & 2.9 & & 6.1 & 0.36 & 33.3 & & 4.9 & 0.36 & 31.4 & & 0.079 & 0.078 & 1.1 & & 0.08 & 0.03 & 6.2 & \\
\hline & Basic & 39 & 0.21 & 0.38 & 1.2 & & 5.3 & 0.57 & 32.6 & & 5.7 & 0.58 & 42.0 & & -0.128 & 0.123 & -1.8 & & 0.19 & 0.04 & 14.8 & \\
\hline \multirow[t]{2}{*}{ Marital status } & Single & 29 & -0.37 & 0.49 & -2.3 & & 3.9 & 0.68 & 23.0 & & 3.4 & 0.71 & 24.2 & * & 0.168 & 0.153 & 2.3 & & 0.14 & 0.05 & 10.7 & \\
\hline & Co-habiting & 98 & 0.62 & 0.22 & 3.2 & & 6.4 & 0.34 & 35.4 & & 5.5 & 0.34 & 36.4 & & -0.013 & 0.073 & -0.2 & & 0.11 & 0.02 & 8.2 & \\
\hline \multirow[t]{2}{*}{ BMI } & $<29.62 \mathrm{~kg} / \mathrm{m}^{2}$ & 64 & 0.48 & 0.28 & 2.5 & & 5.9 & 0.43 & 31.9 & & 5.6 & 0.43 & 36.7 & & 0.009 & 0.094 & 0.1 & & 0.14 & 0.03 & 10.2 & * \\
\hline & $\geq 29.62 \mathrm{~kg} / \mathrm{m}^{2}$ & 63 & 0.44 & 0.29 & 2.4 & & 5.9 & 0.43 & 34.7 & & 4.5 & 0.44 & 31.2 & & 0.030 & 0.093 & 0.4 & & 0.09 & 0.03 & 6.9 & \\
\hline \multirow[t]{2}{*}{ Waist circum-ference } & $<0^{\pi} / \wp$ median & 60 & 0.84 & 0.27 & 4.3 & & 5.9 & 0.44 & 32.0 & & 5.6 & 0.43 & 36.6 & & -0.001 & 0.096 & -0.0 & & 0.10 & 0.03 & 7.4 & \\
\hline & $\geq 0^{x} / \wp$ median & 67 & 0.04 & 0.29 & 0.2 & & 5.9 & 0.43 & 34.3 & & 4.6 & 0.44 & 31.4 & & 0.039 & 0.092 & 0.5 & & 0.12 & 0.03 & 9.8 & \\
\hline \multirow[t]{2}{*}{ Systolic pressure } & $\leq 130 \mathrm{mmHg}$ & 50 & 0.48 & 0.32 & 2.6 & & 5.6 & 0.50 & 31.2 & & 3.9 & 0.50 & 25.9 & & 0.137 & 0.109 & 1.9 & & 0.11 & 0.04 & 8.5 & \\
\hline & $>130 \mathrm{mmHg}$ & 75 & 0.51 & 0.26 & 2.7 & & 6.3 & 0.39 & 35.5 & & 6.0 & 0.40 & 40.0 & & -0.050 & 0.086 & -0.7 & & 0.12 & 0.03 & 8.8 & \\
\hline \multirow[t]{2}{*}{ Diastolic pressure } & $\leq 80 \mathrm{mmHg}$ & 89 & 0.27 & 0.25 & 1.5 & & 5.9 & 0.37 & 32.9 & & 5.0 & 0.38 & 33.4 & & 0.063 & 0.081 & 0.9 & & 0.12 & 0.03 & 9.0 & \\
\hline & $>80 \mathrm{mmHg}$ & 36 & 0.93 & 0.35 & 4.9 & & 6.2 & 0.54 & 36.3 & & 5.6 & 0.55 & 36.9 & & -0.070 & 0.121 & -1.0 & & 0.10 & 0.04 & 8.2 & \\
\hline \multirow{2}{*}{$\begin{array}{l}\text { Antihypertensive } \\
\text { medi-cation }\end{array}$} & No & 36 & 1.07 & 0.35 & 5.4 & & 7.3 & 0.57 & 40.6 & & 6.1 & 0.58 & 40.1 & & 0.128 & 0.127 & 1.9 & & 0.16 & 0.04 & 12.1 & \\
\hline & Yes & 91 & 0.17 & 0.24 & 0.9 & & 5.3 & 0.36 & 30.2 & & 4.7 & 0.36 & 31.7 & & -0.019 & 0.077 & -0.3 & & 0.10 & 0.03 & 7.3 & \\
\hline $\begin{array}{l}\text { Albumin/ } \\
\text { creatinine ratio }\end{array}$ & $\leq 3.5$ & 97 & 0.58 & 0.22 & 3.1 & & 6.7 & 0.34 & 38.1 & * & 5.8 & 0.35 & 39.1 & * & 0.033 & 0.075 & 0.5 & * & 0.12 & 0.02 & 8.7 & \\
\hline
\end{tabular}


Table 2: Developments in primary outcome measures during the study according to baseline variables (Continued)

\begin{tabular}{|c|c|c|c|c|c|c|c|c|c|c|c|c|c|c|c|c|c|c|c|c|}
\hline & $>3.5$ & 30 & -0.05 & 0.45 & -0.3 & & 3.4 & 0.60 & 18.5 & 2.9 & 0.61 & 19.5 & & -0.036 & 0.134 & -0.5 & & 0.10 & 0.04 & 8.2 \\
\hline \multirow{2}{*}{$\begin{array}{l}\text { Fasting plasma } \\
\text { glucose }\end{array}$} & $\leq 7 \mathrm{mmol} / \mathrm{l}$ & 38 & 0.21 & 0.36 & 1.1 & & 6.6 & 0.54 & 37.0 & 6.1 & 0.55 & 42.3 & & 0.064 & 0.119 & 1.0 & * & 0.11 & 0.04 & 7.9 \\
\hline & $>7 \mathrm{mmol} / \mathrm{l}$ & 89 & 0.58 & 0.24 & 3.2 & & 5.6 & 0.37 & 31.5 & 4.6 & 0.37 & 30.5 & & -0.005 & 0.079 & -0.1 & & 0.11 & 0.03 & 8.9 \\
\hline \multirow{3}{*}{$\begin{array}{l}\text { Diabetes } \\
\text { treatment }\end{array}$} & Diet alone & 37 & 0.42 & 0.36 & 2.2 & & 7.0 & 0.57 & 38.8 & 6.7 & 0.55 & 44.8 & * & 0.128 & 0.126 & 2.0 & & 0.16 & 0.04 & 11.3 \\
\hline & Oral agents & 70 & 0.73 & 0.27 & 3.9 & & 5.9 & 0.40 & 33.7 & 5.0 & 0.41 & 32.9 & & -0.016 & 0.089 & -0.2 & & 0.11 & 0.03 & 8.5 \\
\hline & Insulin & 20 & -0.31 & 0.54 & -1.7 & & 3.9 & 0.75 & 21.8 & 2.4 & 0.78 & 16.9 & & -0.041 & 0.159 & -0.6 & & 0.06 & 0.05 & 4.5 \\
\hline \multirow[t]{3}{*}{ Statin treatment ${ }^{b}$} & None & 38 & 1.36 & 0.36 & 7.5 & & 6.3 & 0.56 & 36.1 & 5.3 & 0.57 & 37.8 & & 0.192 & 0.120 & 2.7 & & 0.18 & 0.04 & 13.3 \\
\hline & Un-changed & 78 & 0.16 & 0.26 & 0.9 & & 5.9 & 0.39 & 33.0 & 5.0 & 0.40 & 33.0 & & -0.061 & 0.086 & -0.9 & & 0.08 & 0.03 & 5.8 \\
\hline & Initiated & 11 & -0.33 & 0.62 & -1.7 & & 4.8 & 0.92 & 26.5 & 5.0 & 0.91 & 31.2 & & -0.043 & 0.204 & -0.6 & & 0.13 & 0.07 & 9.7 \\
\hline \multirow[t]{2}{*}{ Smoking } & No & 99 & 0.45 & 0.21 & 2.3 & & 5.9 & 0.33 & 33.2 & 5.2 & 0.34 & 33.9 & & 0.115 & 0.072 & 1.6 & * & 0.09 & 0.02 & 6.7 \\
\hline & Yes & 28 & 0.55 & 0.54 & 3.1 & & 5.6 & 0.72 & 32.6 & 4.9 & 0.77 & 35.0 & & -0.454 & 0.157 & -6.3 & & 0.24 & 0.05 & 18.5 \\
\hline \multirow{2}{*}{$\begin{array}{l}\text { Pain with function } \\
\text { limitation }\end{array}$} & No & 53 & 1.53 & 0.32 & 7.9 & * & 6.0 & 0.49 & 32.4 & 5.7 & 0.48 & 37.7 & & -0.006 & 0.108 & -0.1 & & 0.17 & 0.03 & 12.2 \\
\hline & Yes & 74 & -0.15 & 0.25 & -0.8 & & 5.9 & 0.39 & 34.1 & 4.7 & 0.40 & 32.0 & & 0.036 & 0.084 & 0.5 & & 0.08 & 0.03 & 6.5 \\
\hline \multirow{2}{*}{$\begin{array}{l}\text { Cardiovascular } \\
\text { disease }\end{array}$} & No & 66 & 1.03 & 0.23 & 5.2 & * & 6.0 & 0.39 & 33.3 & 5.5 & 0.38 & 35.2 & & 0.012 & 0.084 & 0.2 & & 0.12 & 0.02 & 8.9 \\
\hline & Yes & 45 & -0.77 & 0.37 & -4.3 & & 5.7 & 0.54 & 32.6 & 4.1 & 0.55 & 29.4 & & -0.082 & 0.118 & -1.1 & & 0.05 & 0.03 & 3.8 \\
\hline
\end{tabular}

$n$ is number of patients. $\Delta$ is a measure of absolute increase defined as the difference between the (subgroup-specific) modelled baseline and the 18-month examination outcome. The corresponding increase, relative to the modelled baseline examination outcome, is indicated under \%. ${ }^{a}$ Differences between subgroups are assessed by a Wald test for the time-subgroup interaction. To account for multiple testing, the tests that remained significant after controlling for the false discovery rate at $5 \%$ are indicated with $a{ }^{*} .{ }^{b}$ Indicates whether patients had unchanged statin treatment during the study or stated statin treatment during the study. 
multivariate model including all the baseline variables listed in Table 2 as predictors and $\mathrm{VO}_{2 \max }$ as outcome, only CVD $(\mathrm{p}=0.001)$ and pain with function limitation ( $p=0.023$ ) were statistically significant. Patients without cardiovascular disease or pain from function limitation increased their $\mathrm{VO}_{2 \max }$ by $5.2 \%(\mathrm{p}<0.0001)$ and $7.9 \%$ $(\mathrm{p}=0.0008)$, respectively. All subgroups increased their muscle strength, but high age and microalbuminuria were associated with relatively small improvements in muscle strength tests.

\section{Secondary outcome measures}

Waist circumference, BMI and fasting plasma glucose did not change, and there was a slight increase in systolic and diastolic pressure. The lipid profile improved (Table 3).

\section{The course of the intervention}

Ten of the 127 participants were referred to initial supervision by a physiotherapist, and two attended local fitness centres, but most chose lifestyle exercise or self-managed home-based exercise programmes or both. The programmes included aerobic training using an exercise bike and resistance training with weights or use of own body weight [2]. The intervention was safe and well tolerated with a dropout rate of $19.6 \%$ despite a high degree of comorbidity (Table 1). One maximal exercise test was stopped because the patient felt unwell, but there were no other complications associated with the test procedures except for slight tenderness of joints and muscles. Reasons for not performing all three tests at the final session were musculoskeletal disease (14/102), blood pressure $>180 / 110(7 / 102)$, heart disease (9/102), and acute illness (1/102). The extra time attributed to the expansion of the usual diabetes control to include a fitness consultation was estimated to be $10 \mathrm{~min}$.

\section{Discussion}

In this 18-month uncontrolled intervention study, repeated fitness consultations including fitness testing

\begin{tabular}{|c|c|c|c|}
\hline Secondary outcome measure & $\Delta$ & SE & $p$ \\
\hline Waist circumference $(\mathrm{cm})$ & 0.28 & 0.54 & 0.93 \\
\hline $\mathrm{BMI}\left(\mathrm{kg} / \mathrm{m}^{2}\right)$ & 0.13 & 0.09 & 0.13 \\
\hline Systolic blood pressure $(\mathrm{mmHg})$ & 2.50 & 1.83 & 0.037 \\
\hline Diastolic blood pressure $(\mathrm{mmHg})$ & 1.38 & 0.92 & 0.0009 \\
\hline Fasting plasma glucose (mmol/l) & 0.12 & 0.19 & 0.79 \\
\hline Total cholesterol (mmol/l) & -0.25 & 0.08 & 0.006 \\
\hline LDL-cholesterol (mmol/l) & -0.31 & 0.07 & $<0.0001$ \\
\hline Triglycerides (mmol/l) & -0.09 & 0.14 & 0.66 \\
\hline
\end{tabular}

$\Delta$ is defined as the difference between the modelled baseline and the 18month examination outcome. SE, standard error. $n=127$. For baseline values see Table 1. and motivational interviewing resulted in the participants having increased muscle strength and $\mathrm{VO}_{2 \max }$, and an improved lipid profile, while $\mathrm{HbA}_{1 \mathrm{c}}$ remained unchanged on a low level. Among the secondary outcome measures, waist circumference, BMI and fasting plasma glucose were unchanged, blood pressures increased slightly, whereas total cholesterol and LDLcholesterol decreased.

\section{Comparison with relevant literature}

In the studies by David et al. [31,32], six months of supervised progressive high-intensity resistance training three times a week in older (mean age 67.6 years) type 2 diabetic patients with few comorbidities resulted in a 41.7\% increase in upper body muscle strength and a $28.0 \%$ increase in lower body muscle strength. Additional home-based resistance training for 6 months was effective in maintaining the gymnasium-based improvements in muscle strength. These results are comparable with the increase and maintenance of muscle strength attained in the present study considering its less intensive intervention (Table 2 and Figure 2).

A meta-analysis has reported an $11.8 \%$ increase of $\mathrm{VO}_{2 \max }$ in structured aerobic exercise studies with the following average characteristics: 3.4 sessions per week, 49 min. per session for 20 weeks with exercise intensities of $50-75 \%$ of $\mathrm{VO}_{2 \max }$ [11]. The study populations in the meta-analysis were selected so they had a minimum of cardiovascular or orthopaedic limitations and were on average 12 years younger than the present study population. During our intervention, there was a slight (2.4\%) but significant increase in $\mathrm{VO}_{2 \max }$ for the whole group. There was a more substantial increase of $7,9 \%$ in the subgroup $(\mathrm{n}=53)$ without function-limiting pain and $5,2 \%$ in the subgroup $(n=61)$ without CVD (Table 2$)$. In light of these post hoc explanatory subgroup analyses, our study indicated that physical tests and motivational interviewing had an impact comparable with supervised exercise sessions on muscle strength and $\mathrm{VO}_{2 \max }$.

There is a steep inverse relationship between cardiorespiratory fitness and mortality in men with documented diabetes [5]. This could mean that an improvement in fitness, like the one we observed, is of clinical significance. In an observational prospective study of men, an increase of $7.0 \mathrm{ml} / \mathrm{kg} / \mathrm{min}$ in $\mathrm{VO}_{2 \max }$ over 4.9 years was associated with an estimated reduction of $30 \%$ in mortality risk during the following 5.1 years [7]. $\mathrm{HbA}_{1 \mathrm{c}}$ did not change in participants during the present study, which perhaps is explained by the low baseline level of $\mathrm{HbA}_{1 \mathrm{c}}$ [33]. The increase in HDL-cholesterol may be a result of increased muscle strength and increased $\mathrm{VO}_{2 \max }$ [34]. The intervention had no impact on BMI and waist circumference. Nevertheless the intervention may have had a clinically significant effect on health as the inverse gradient 
between fitness and mortality in men with documented diabetes mentioned above is independent of BMI $[4,5]$. The improvement in glycaemic control following endurance and strength training may also be observed with unchanged BMI [35].

\section{Strengths and limitations of the study}

The study was done in the setting of a primary health care unit using primary care practitioners to carry out the intervention. The whole town was aware of the project, which made it difficult and demanding to do a randomised controlled trial, e.g. using the idea of waiting list controls. Unlike most other studies, patients with cardiovascular or musculoskeletal disease were not excluded [11]. The idea of physical testing was completely new to the patients and this, in combination with the relatively high median age, was probably the major reason for the low participation rate.

The lack of a control group is a major limitation of the study which leaves the possibility that the improvements in outcomes could be due to the general development in the natural history of type 2 diabetes and, for the physical tests in particular, to some degree of habituation. However, it is unlikely that the observed improvements in cardio-respiratory fitness and muscle strength can be explained entirely by these effects. Firstly, control groups in previous randomised studies show a decrease in $\mathrm{VO}_{2 \max }$ of $1 \%$ over a period of 20 weeks and small nonsignificant increases of $1.5 \%$ and $5 \%$ in upper and lower body strength $[11,31]$. Secondly, the expected age-related decline in muscle strength and $\mathrm{VO}_{2 \max }$ over 18 months can be estimated to be $2.5 \%$ and $2.2 \%$ respectively in the population of the present study $[2,36]$. Thirdly, if habituation explained the improvement, the same development should be expected in the different subgroups, and this is not the case (Table 2).

The arm curl test and the chair stand test are validated methods for measuring muscle strength in upper and lower extremities. These tests have a high test-retest reliability, are simple to use in everyday practice, and can be done by nearly all patients [2] (Figure 1). Until now, experience with these tests has been limited to a population over 60 years of age. In this study, it was assumed that they could also be used with younger people to measure changes in muscle strength. The bicycle ergometer test is known to give an accurate estimate of $\mathrm{VO}_{2 \max }[24,27]$, but about one third of the type 2 diabetic participants were unable to do the test because of contraindications and comorbidity (Figure 1). However, all the participants were able to perform at least one of the three tests so all got a result that could be used in the motivational interview.

\section{Conclusion}

Clinical implementation of increased physical activity in the treatment of type 2 diabetes is still far from being standard practice. Our results indicate that physical testing combined with motivational interviewing can be done in a primary health care setting. Here, a fitness consultation tailored to the individual patient, his/her comorbidities and conditions in the local area can be incorporated into the diabetes programme to improve patients' muscle strength and cardio-respiratory fitness. The extra workload caused by fitness consultations in primary care could for instance be carried by practice nurses or physiotherapists who have received training in motivational interviewing and physical testing. Randomised trials are needed to confirm our findings and to optimise recommendations for the content and the frequency of the fitness consultations [37].

\section{Funding}

The study was supported by The Danish Board of Health and the Region of West-Zealand.

\section{Acknowledgements}

We acknowledge the contributions of the participating patients. We thank our colleagues P. E. Elkjær-Andersen, J. Essam, J. Knabe, S. Sand, and A. Stærke for doing the fitness consultations and L. Nielsen, C. Krumphardt, J. Lynge Olsen and W. Karlslund for technical and logistical support. T. Thorsen gave instruction to the GPs in motivational interviewing. We thank the two reviewers for their valuable comments and suggestions.

\section{Author details}

${ }^{1}$ General practice, Korsør, Denmark. ${ }^{2}$ The Research Unit for General Practice and Section of General Practice, Department of Public Health, University of Copenhagen, Copenhagen, Denmark.

\section{Authors' contributions}

HL made substantial contributions to conception and design of the study, planned and conducted it, collected, analysed and interpreted data and drafted the manuscript,. VS did the statistical analysis and interpreted data and has been involved in drafting the manuscript and revising it critically for important intellectual content.,. NO made substantial contributions to conception, design, analysis and interpretation. He has revised the manuscript critically for important intellectual content.

All authors read and approved the final manuscript.

\section{Competing interests}

The authors declare that they have no competing interests.

Received: 17 October 2009 Accepted: 3 November 2010 Published: 3 November 2010

\section{References}

1. Wei M, Gibbons LW, Kampert JB, Nichaman MZ, Blair SN: Low cardiorespiratory fitness and physical inactivity as predictors of mortality in men with type 2 diabetes. Ann Intern Med 2000, 132:605-611.

2. Rikli RE, Jones CJ: Senior Fitness Test Manual. Human Kinetics, Champaign IL; 2001 .

3. Rantanen T: Muscle strength, disability and mortality. Scand J Med Sci Sports 2003, 13:3-8. 
4. Hu G, Jousilahti P, Barengo NC, Qiao Q, Lakka TA, Tuomilehto J: Physical activity, cardiovascular risk factors, and mortality among Finnish adults with diabetes. Diabetes Care 2005, 28:799-805.

5. Church TS, Cheng YJ, Earnest CP, Barlow CE, Gibbons LW, Priest EL, Blair SN: Exercise capacity and body composition as predictors of mortality among men with diabetes. Diabetes Care 2004, 27:83-88.

6. Blair SN, Kohl HW III, Paffenbarger RS Jr, Clark DG, Cooper KH, Gibbons LW Physical fitness and all-cause mortality. A prospective study of healthy men and women. Jama 1989, 262:2395-2401.

7. Blair SN, Kohl HW III, Barlow CE, Paffenbarger RS Jr, Gibbons LW, Macera CA Changes in physical fitness and all-cause mortality. A prospective study of healthy and unhealthy men. Jama 1995, 273:1093-1098.

8. Plotnikoff RC, Taylor LM, Wilson PM, Courneya KS, Sigal RJ, Birkett N, Raine K, Svenson LW: Factors associated with physical activity in Canadian adults with diabetes. Med Sci Sports Exerc 2006, 38:1526-1534.

9. Gu K, Cowie CC, Harris Ml: Mortality in adults with and without diabetes in a national cohort of the U.S. population, 1971-1993. Diabetes Care 1998, 21:1138-1145.

10. Struijs JN, Baan CA, Schellevis FG, Westert GP, van den Bos GA: Comorbidity in patients with diabetes mellitus: impact on medical health care utilization. BMC Health Serv Res 2006, 6:84

11. Boule NG, Kenny GP, Haddad E, Wells GA, Sigal RJ: Meta-analysis of the effect of structured exercise training on cardiorespiratory fitness in Type 2 diabetes mellitus. Diabetologia 2003, 46:1071-1081.

12. Boule NG, Weisnagel SJ, Lakka TA, Tremblay A, Bergman RN, Rankinen T, Leon AS, Skinner JS, Wilmore JH, Rao DC, et al: Effects of exercise training on glucose homeostasis: the HERITAGE Family Study. Diabetes Care 2005, 28:108-114.

13. Boule NG, Bouchard C, Tremblay A: Physical fitness and the metabolic syndrome in adults from the Quebec Family Study. Can J Appl Physiol 2005, 30:140-156.

14. Verity LS, Ismail AH: Effects of exercise on cardiovascular disease risk in women with NIDDM. Diabetes Res Clin Pract 1989, 6:27-35.

15. Ibanez J, Izquierdo M, Arguelles I, Forga L, Larrion JL, Garcia-Unciti M, Idoate F, Gorostiaga EM: Twice-weekly progressive resistance training decreases abdominal fat and improves insulin sensitivity in older men with type 2 diabetes. Diabetes Care 2005, 28:662-667.

16. Nielsen PJ, Hafdahl AR, Conn VS, Lemaster JW, Brown SA: Meta-analysis of the effect of exercise interventions on fitness outcomes among adults with type 1 and type 2 diabetes. Diabetes Res Clin Pract 2006, 74:111-120.

17. Rubak S, Sandbaek A, Lauritzen T, Christensen B: Motivational interviewing: a systematic review and meta-analysis. Br J Gen Pract 2005, 55:305-312.

18. Kirk AF, Mutrie N, Maclntyre PD, Fisher MB: Promoting and maintaining physical activity in people with type 2 diabetes. Am J Prev Med 2004, 27:289-296.

19. Rollnick S, Mason P, Butler C: Health Behavior Change: A guide for practitioners. London: Churchill Livingstone; 1999.

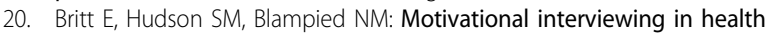
settings: a review. Patient Educ Couns 2004, 53:147-155.

21. Di Loreto C, Fanelli C, Lucidi P, Murdolo G, De CA, Parlanti N, Santeusanio F, Brunetti P, De FP: Validation of a counseling strategy to promote the adoption and the maintenance of physical activity by type 2 diabetic subjects. Diabetes Care 2003, 26:404-408.

22. Kirk AF, Barnett J, Mutrie N: Physical activity consultation for people with Type 2 diabetes. Evidence and guidelines. Diabet Med 2007, 24:809-816.

23. Jette AM, Rooks D, Lachman M, Lin TH, Levenson C, Heislein D, Giorgetti MM, Harris BA: Home-based resistance training: predictors of participation and adherence. Gerontologist 1998, 38:412-421.

24. American college of sports medicine: ACSM's Guidelines for Exercise Testing and Presciption. Lippincott Williams \& Wilkins, Philadelphia; 2000.

25. Hu FB, Stampfer MJ, Solomon C, Liu S, Colditz GA, Speizer FE, Willett WC, Manson JE: Physical activity and risk for cardiovascular events in diabetic women. Ann Intern Med 2001, 134:96-105.

26. Di Loreto C: Make Your Diabetic Patients Walk. Diabetes Care 2005, 28:1295-1302.

27. Storer TW, Davis JA, Caiozzo VJ: Accurate prediction of VO2max in cycle ergometry. Med Sci Sports Exerc 1990, 22:704-712.

28. Sigal RJ, Kenny GP, Wasserman DH, Castaneda-Sceppa C, White RD: Physical activity/exercise and type 2 diabetes: a consensus statement from the American Diabetes Association. Diabetes Care 2006, 29:1433-1438.
29. Verbeke G, Molenberghs G: Linear Mixed Models for Longitudinal Data Springer series in statistics. Springer, New York; 2000.

30. Benjamini $Y, H$ Y: "Controlling for the false discovery rate: a practical and powerful approach to multiple testing". Journal of the Royal Statistical Society 1995, 57(1):289-300.

31. Dunstan DW, Daly RM, Owen N, Jolley D, De Court, Shaw J, Zimmet P: High-intensity resistance training improves glycemic control in older patients with type 2 diabetes. Diabetes Care 2002, 25:1729-1736.

32. Dunstan DW, Daly RM, Owen N, Jolley D, Vulikh E, Shaw J, Zimmet P. Home-based resistance training is not sufficient to maintain improved glycemic control following supervised training in older individuals with type 2 diabetes. Diabetes Care 2005, 28:3-9.

33. Sigal RJ, Kenny GP, Boule NG, Wells GA, Prud'homme D, Fortier M, Reid RD, Tulloch $H$, Coyle D, Phillips $P$, et al: Effects of aerobic training, resistance training, or both on glycemic control in type 2 diabetes: a randomized trial. Ann Intern Med 2007, 147:357-369.

34. Balducci S, Leonetti F, Di MU, Fallucca F: Is a long-term aerobic plus resistance training program feasible for and effective on metabolic profiles in type 2 diabetic patients? Diabetes Care 2004, 27:841-842.

35. Cauza E, Hanusch-Enserer U, Strasser B, Ludvik B, Metz-Schimmerl S, Pacini G, Wagner O, Georg P, Prager R, Kostner K, et al: The relative benefits of endurance and strength training on the metabolic factors and muscle function of people with type 2 diabetes mellitus. Arch Phys Med Rehabil 2005, 86:1527-1533.

36. Paterson DH, Cunningham DA, Koval JJ, St Croix CM: Aerobic fitness in a population of independently living men and women aged 55-86 years. Med Sci Sports Exerc 1999, 31:1813-1820.

37. Praet SF, van Loon LJ: Exercise: the brittle cornerstone of type 2 diabetes treatment. Diabetologia 2008, 51:398-401.

\section{Pre-publication history}

The pre-publication history for this paper can be accessed here: http://www.biomedcentral.com/1471-2296/11/83/prepub

doi:10.1186/1471-2296-11-83

Cite this article as: Lohmann et al:: Fitness consultations in routine care of patients with type 2 diabetes in general practice: an 18-month nonrandomised intervention study. BMC Family Practice 2010 11:83.

\section{Submit your next manuscript to BioMed Central and take full advantage of:}

- Convenient online submission

- Thorough peer review

- No space constraints or color figure charges

- Immediate publication on acceptance

- Inclusion in PubMed, CAS, Scopus and Google Scholar

- Research which is freely available for redistribution

Submit your manuscript at www.biomedcentral.com/submit
Biomed Central 